\title{
Application of highly sensitive, modified glass substrate-based immuno-PCR on the early detection of nasopharyngeal carcinoma
}

\author{
Tzu-Wei Wang a,b,c , Hsiang-Yin Lu ${ }^{\text {b,c }}$, Pei-Jen Lou ${ }^{\text {d,**, Feng-Huei Lin }}{ }^{\text {b,c,* }}$ \\ a Tissue Engineering Laboratories, Brigham and Women's Hospital, Harvard Medical School and VA Boston Healthcare System, MA, USA \\ ${ }^{\mathrm{b}}$ Institute of Biomedical Engineering, College of Medicine, National Taiwan University, Taipei, Taiwan, ROC \\ ${ }^{c}$ College of Engineering, National Taiwan University, Taipei, Taiwan, ROC \\ ${ }^{\mathrm{d}}$ Department of Otolaryngology, National Taiwan University Hospital, Taipei, Taiwan, ROC
}

\section{A R T I C L E I N F O}

\section{Article history:}

Received 2 June 2008

Accepted 10 July 2008

Available online 26 August 2008

\section{Keywords:}

Surface modification

Silane

Immunoassay

Immuno-PCR

Cancer

\begin{abstract}
A B S T R A C T
In this study, we investigated the utilization of highly sensitive immuno-PCR (IPCR) method as a powerful tool to detect NPC in early disease stage. We established a substrate-ELISA platform as a model system for evaluation of the feasibility of our idea after surface modification process on glass beads. Therein the DNA-antibody conjugation was added to sensitize prior enzyme substrate-antibody complex. In the study, the detection efficiency of two different systems regarding sensitivity, affinity, and specificity was evaluated. Moreover, to show the efficacy of our IPCR system, commercialized ELISA kit was also included for comparison with our IPCR glass substrate-based capture system. The surface physical properties of the modified substrates were also tested with atomic force microscopy and X-ray photoelectron spectroscopy, together with the measurement of the water contact angle. In the results, various factors in the production of IPCR detection system were determined to maximize the effect on assay performance, including the modification of the glass surface properties, primary and secondary antibody optimal concentrations, and biotinylated reporter DNA concentration. We found that the sensitivity of IPCR was approximately over two order magnitude higher than that of conventional ELISA method. The result suggests that our IPCR system could be an applicable and reliable tool for early detection of NPC.
\end{abstract}

(c) 2008 Elsevier Ltd. All rights reserved.

\section{Introduction}

Incidence of nasopharyngeal carcinoma (NPC) has remained high in endemic regions. Poor prognosis often resulted from delayed clinical diagnostics because of the occurrence of NPC usually in deep anatomical site and along with vague symptoms. Epstein-Barr virus nuclear antigen (EBNA1) is a DNA-binding nuclear phosphoprotein, which is required for the replication and maintenance of the episomal Epstein-Barr virus (EBV) genome. Directing EBNA1 expression to lymphocytic cells in transgenic mice has been shown to result in B-cell lymphomas suggesting that EBNA1 may have a direct role in oncogenesis [1]. EBV-encoded RNA signal is present in all nasopharyngeal carcinoma cells, and diagnosis of the disease is possible through the detection of raised antibodies against EBV [2]. However, so far the analysis of the pathophysiological role of EBNA1 in human plasma is difficult to

\footnotetext{
* Corresponding author. Institute of Biomedical Engineering, College of Medicine, National Taiwan University, Taipei, Taiwan, ROC. Tel.: +8862 23912641; fax: +8862 23940049.

** Corresponding author.

E-mail address: double@ha.mc.ntu.edu.tw (F.-H. Lin).
}

achieve using conventional assays because of the low concentrations of EBNA1.

An immunoassay is defined as an analytical method that uses antibodies or antibody-related reagents for the determination of sample components [3]. The selective nature of antibody binding allows these reagents to be employed in the development of methods that are highly specific and that can often be used directly with even complex biological matrixes such as blood, plasma, or urine. To extend the scope of PCR to the high-sensitivity detection of proteins, we here established an immuno-PCR (IPCR) system to take advantages of specific conjugates comprising an antibody and a DNA marker fragment. Combining the versatility of enzyme-linked immunosorbent assays (ELISAs) with the amplification power and sensitivity of the PCR, IPCR is based on chimeric conjugates of specific antibodies and nucleic acid molecules, the latter of which are used as markers to be amplified by PCR for signal generation. The enormous efficiency of nucleic acid amplification typically leads to a $100-10,000$-fold increase in sensitivity, as compared with the analogous enzyme-amplified immunoassay $[4,5]$. In addition to the great increase in sensitivity, IPCR offers the opportunity to freely choose the sequence of the DNA marker and hence opens up access to an almost unlimited range of specifically labeled antibodies, 
which even enable multiplex detection of various different antigens [6]. The specific and sensitive detection of these markers is considered to be one of the most important challenges in the monitoring of many diseases, such as cancer and autoimmune diseases [7].

Owing to the versatility and high affinity of the biotin-streptavidin binding, we have explored and utilized this coupling system to generate IPCR reagents. In principle, the glass substrates were used to conjugate with epoxy-terminated silane group for binding with anti-EBNA1. After conjugating with the anti-EBNA1 IgA antibody in human plasma, biotinylated secondary antibody was then applied on it. The free streptavidin binding sites were linked to the biotinylated reporter plasmid DNA. The signal was amplified by conventional PCR and the products were analyzed by gel electrophoresis. In this study, we were interested in further enhancing the sensitivity of antigen-antibody detection systems. This should facilitate the specific detection of rare antigens, such as EBNA1, which are present only in very small numbers, and thus could expand the application of this technique in early detection of nasopharyngeal carcinoma.

\section{Materials and methods}

\subsection{Surface modification and activation of glass substrates}

The surface activation and modification process were carried out as previously described by Wong and Krull [8]. In brief, untreated slides were washed with ethanol and then etched by immersion in piranha solution $\left(70 \% \mathrm{H}_{2} \mathrm{SO}_{4}+30 \% \mathrm{H}_{2} \mathrm{O}_{2}\right)$ at room temperature for $1 \mathrm{~h}$. Subsequently, the slides were cleaned by sonification for $15 \mathrm{~min}$. All slides were dried with nitrogen. They were then rinsed several times in water, washed in ethanol and derivatised in the 2.5\% 3-glycidoxypropyltrimethoxysilane (GPTS) solution at $60^{\circ} \mathrm{C}$ for $4 \mathrm{~h}$ followed by a sonification step. After silanisation, GPTS-treated slides were washed thoroughly with $95 \%$ ethanol. The slides were finally baked in oven for cross-linking and well preserved for the further experiments.

\subsection{Characterization}

X-ray photoelectron spectroscopy (XPS) analysis was performed with a VG MICROTECH, MT-500, UK spectrometer. The X-ray source was unmonochromated $\mathrm{Mg} \mathrm{K} \alpha$ and the sample size was $1 \times 1 \mathrm{~cm}^{2}$. The excitation voltage was $1253.6 \mathrm{eV}$. The pass energy of $192 \mathrm{eV}$ was used for low resolution survey and elemental composition analysis, whereas a pass energy of $48 \mathrm{eV}$ was used for high resolution scans.

The atomic force microscope (AFM) images of the glass surfaces were obtained from a Digital Instruments Nanoscope Atomic Force Microscope (Asylum Research, Santa Barbara, CA, USA). The imaging was done in air in tapping mode. The AFM tip was made of silicon nitride with a spring constant of $0.12 \mathrm{~N} \mathrm{~m}^{-1}$ and a nominal radius of 20-60 $\mathrm{nm}$. The software used to process the images was Nanoscope IIIa (Santa Barbara, CA, USA).

\subsection{Wettability measurements}

A $5 \mu \mathrm{L}$ droplet of double-distilled water was deposited near the edge of an untreated or GPTS-modified glass slide. A light microscope that was equipped with a protractor was placed at its side as well as the illumination source so that the light would travel parallel to the bench top. A sample stage supported the slide enabling the shadow of the water droplet to be observed. Each measurement was made within $1 \mathrm{~min}$ of water deposition and was repeated for five other spots along the edge of the slide.

\subsection{Immuonochemistry analysis}

The commercialized Super Sensitive ${ }^{\mathrm{TM}}$ Non-Biotin HRP Detection System (Invitrogen, CA, USA) was purchased to evaluate the capability of protein immobilization on glass substrate. In brief, silanized slide was grafted with mouse IgG for reaction overnight at $4{ }^{\circ} \mathrm{C}$, and then washed with PBS buffer. Supper enhencer ${ }^{\mathrm{TM}}$ reagent was dropped onto the slide, incubated for $20 \mathrm{~min}$ at room temperature followed by washing with PBS. Poly-HRP reagent was finally added to react for $30 \mathrm{~min}$ and colored by DAB solution.

\subsection{ELISA}

Hundred microliter of diluted serum specimens, positive control, and negative control was added into microplate wells, respectively. Incubate at $37^{\circ} \mathrm{C}$ for $1 \mathrm{~h}$. The serial dilution of enzyme-antibody conjugates was then added and incubated at $37^{\circ} \mathrm{C}$ for $30 \mathrm{~min}$. Tetramethylbenzidine (TEB) solution was used for staining. The reaction was stopped by $1 \mathrm{~N} \mathrm{HCl}$ addition. The results were measured at the wavelength of $450 \mathrm{~nm}$ by spectrophotometer.

\subsection{Modeling of immuno-PCR}

The detection protocol used is modified according to the conventional ELISA methods [9]. In brief, $50 \mu \mathrm{l}$ of EBNA1 protein $(10 \mu \mathrm{g} / \mathrm{ml})$ was added onto glass substrate for conjugation with immobilized silane groups for $4 \mathrm{~h}$ at $37^{\circ} \mathrm{C}$. Unbound antigens were then aspirated and washed three times with washing buffer containing $10 \mathrm{~mm}$ Tris $\mathrm{pH} 7.3,150 \mathrm{~mm} \mathrm{NaCl}$. Substrate surface was blocked by incubation with $10 \mathrm{mM}$ Tris/ $\mathrm{HCl}$ for $1 \mathrm{~h}$ at $37{ }^{\circ} \mathrm{C}, \mathrm{pH} 7.6$, containing $6 \%(\mathrm{w} / \mathrm{v})$ non-fat milk powder, $0.2 \%(\mathrm{w} / \mathrm{v}) \mathrm{NaN}_{3}, 0.05 \%$ Tween-20, and 5 mm EDTA. NPC patient's serum with anti-EBNA1 IgA antibody was applied and then incubated for $1 \mathrm{~h}$ at RT. After washing, samples were further incubated for $1 \mathrm{~h}$ at RT with biotinylated goat antihuman IgA secondary antibody (KPL Europe). After that, the specimens were washed and incubated for $30 \mathrm{~min}$ at RT with $100 \mathrm{ng} / \mathrm{ml}$ streptavidin (KPL Europe). $1 \mathrm{ng} / \mathrm{ml}$ biotinylated PCR target DNA (Sigma) was incubated with the specimens for $30 \mathrm{~min}$ at RT. Unbound target DNA was rigorously removed by washing several times with PBS/Tween solution (Zymed Laboratories Inc.). The brief scheme is illustrated in Fig. 1.

After addition of commercialized PCR kit reagents, contents were subjected to 30 cycles of PCR amplification (PCR Thermocycler, Corbett Life Science, Australia). PCR was performed in $50 \mu \mathrm{l}$ of $50 \mathrm{~mm} \mathrm{KCl}$ in $10 \mathrm{mM}$ Tris/ $\mathrm{HCl}, \mathrm{pH} 8.3$, containing $1 \mathrm{~mm}$ $\mathrm{Mg}^{2+}, 50 \mu \mathrm{m}$ of dNTP (PCR Master Mix, GeneMark), 50 pmole of each primer. A primer set nested to those used above for production of biotinylated PCR target DNA was used, and gave a 235 base-pair PCR product (sense primer sequence corresponding to pHSP-70: 5'-CTCCAGCCGACAAGAAGC-3'; antisense primer sequence: $5^{\prime}$-ACGGTGTTGTGGGGGTTCAGG- $3^{\prime}$ ). Tests were initially heated to $95^{\circ} \mathrm{C}$ and held at this temperature for $5 \mathrm{~min}$, then subjected to 30 cycles of $55^{\circ} \mathrm{C}, 30 \mathrm{~s}$, $72{ }^{\circ} \mathrm{C}, 30 \mathrm{~s}, 94^{\circ} \mathrm{C}, 30 \mathrm{~s}$, followed by $72{ }^{\circ} \mathrm{C}$ for $15 \mathrm{~min}$, then cooling to $4{ }^{\circ} \mathrm{C}$. Resulting biotinylated DNA was purified using a QIAGEN Gel/PCR DNA Fragments Extraction Kit (Qiagen, USA.) and stored frozen in batches at $-20^{\circ} \mathrm{C}$. The resulting PCR products were analyzed by $1.5 \%$ agarose gel electrophoresis after staining with ethidium bromide.

\section{Results}

\subsection{Characteristics of glass substrate surface properties}

\subsubsection{Water contact angle}

The water contact angle was measured to confirm the glass surface modification process. In Fig. 2, the water contact angle on the surface of unmodified glass substrate was $40.75^{\circ} \pm 3.77$. After piranha solution treatment, a layer of hydroxyl groups was formed

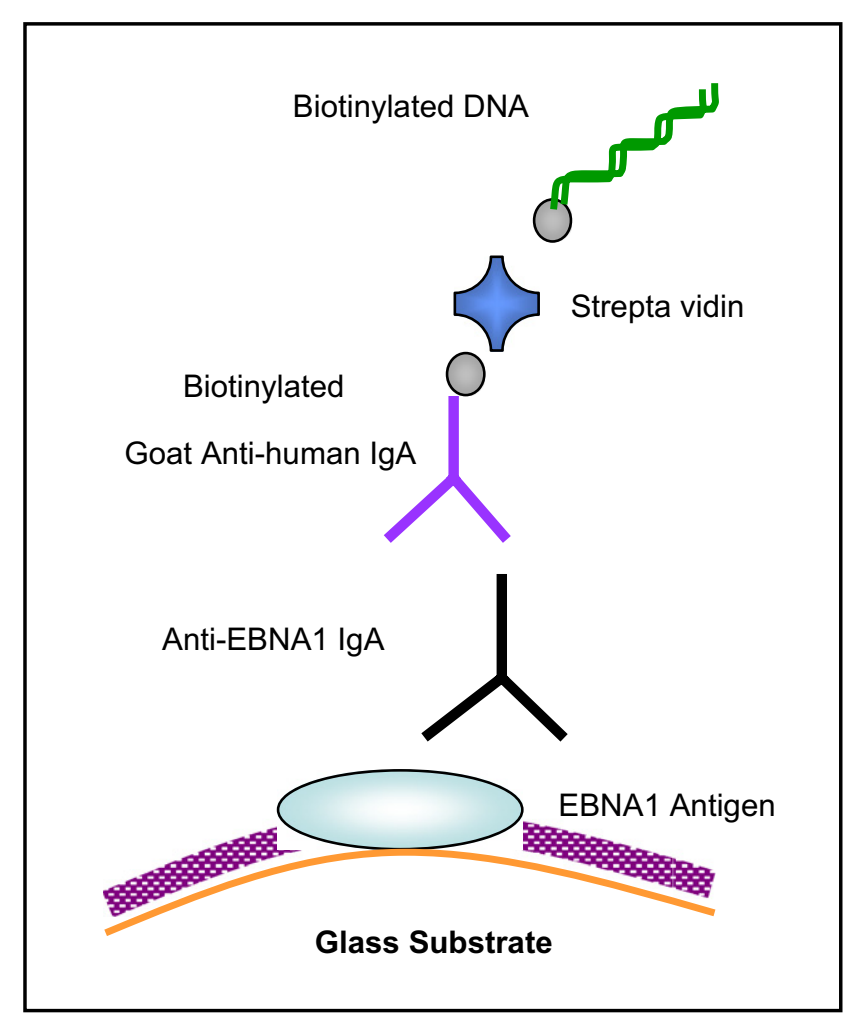

Fig. 1. The scheme of modeling process of immuno-PCR. 

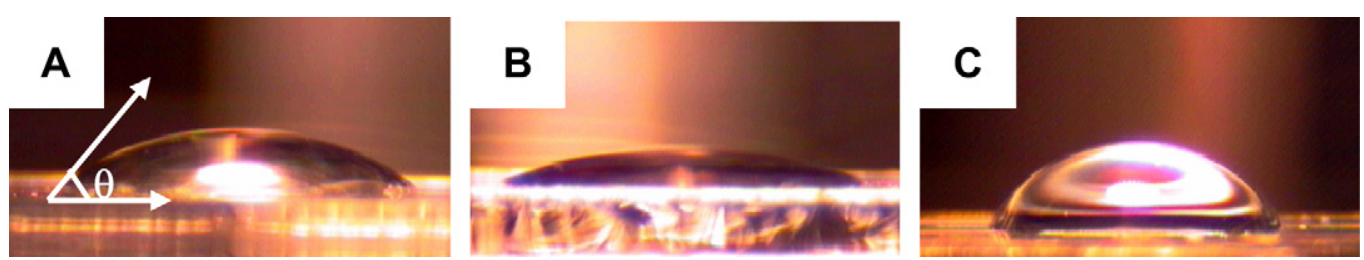

Fig. 2. The measurement of water contact angle $(\theta)$ on the surface of (A) untreated glass, (B) piranha-treated glass, and (C) GPTS-treated glass.

on the outer surface area resulting in more hydrophilic property. The water contact angle was reduced to $8.75^{\circ} \pm 4.11$. The angle shifted to $51.20^{\circ} \pm 3.83$ after silanisation. This phenomenon was probably attributed to the polarity of tailed epoxide groups on the silanized glass surface being not as hydrophilic as hydroxyl groups.
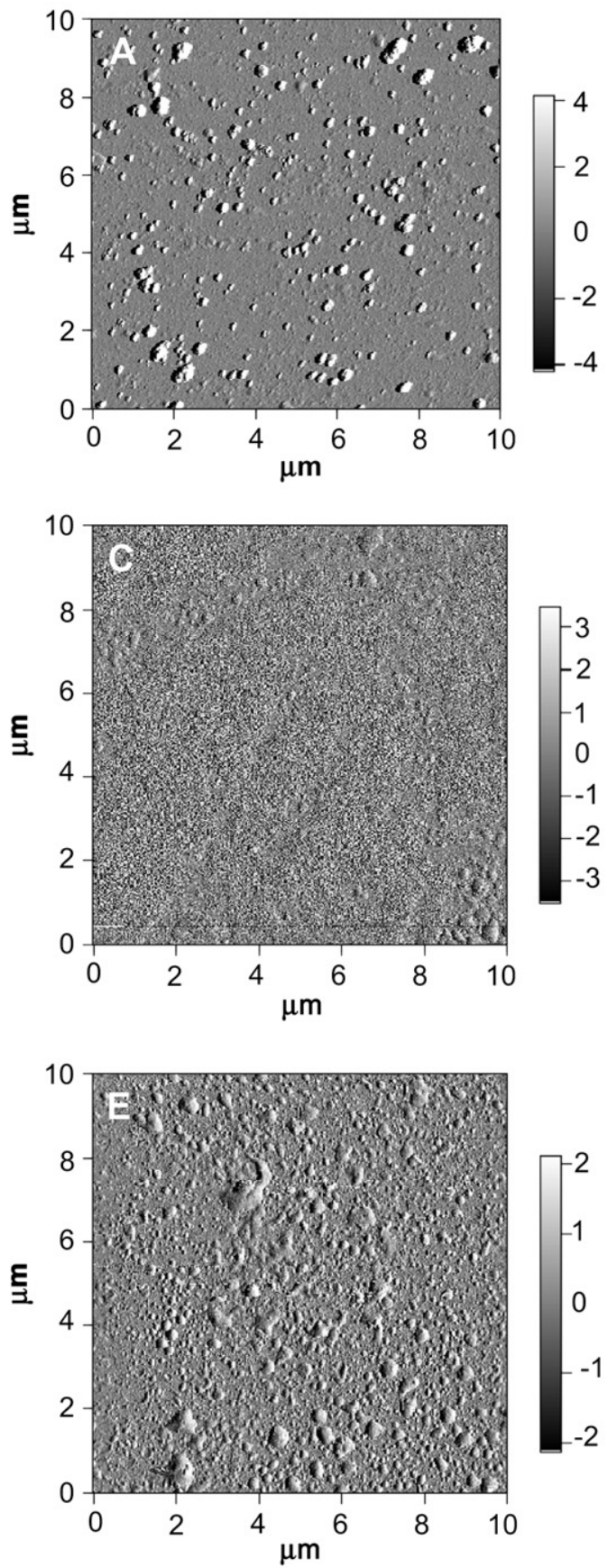

\section{AFM}

The surface morphology of unmodified and modified glass substrate is characterized in Fig. 3. The surface was uneven before any treatment (Fig. 3A, B). After piranha etching, the surface was more smooth (Fig. 3C, D). The surface became slight roughness after
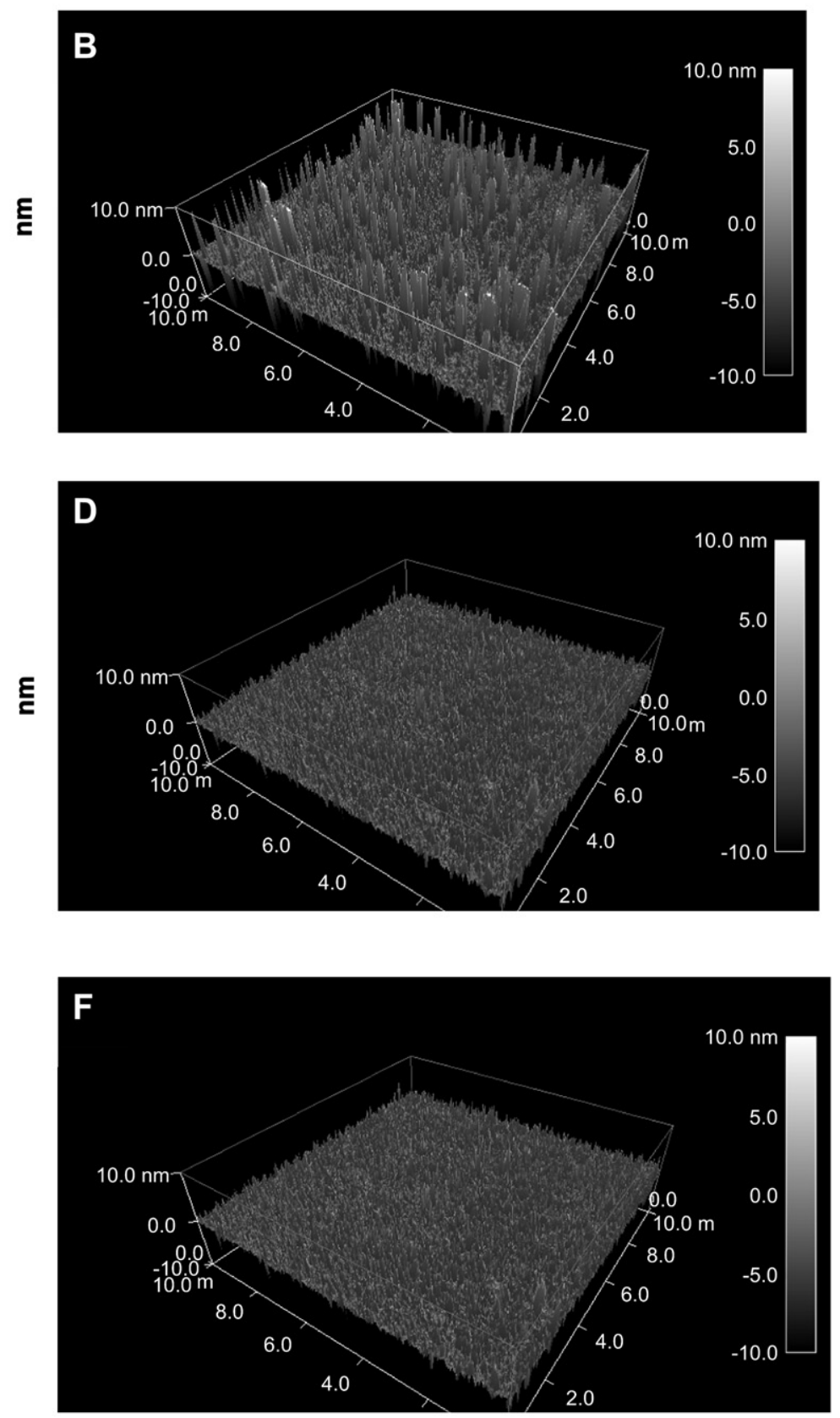

Fig. 3. AFM images of (A) untreated glass, (C) piranha-treated glass, and (E) GPTS-treated glass. (A, C, E) 2D images and (B, D, F) 3D images. 
$\mathrm{Si}$
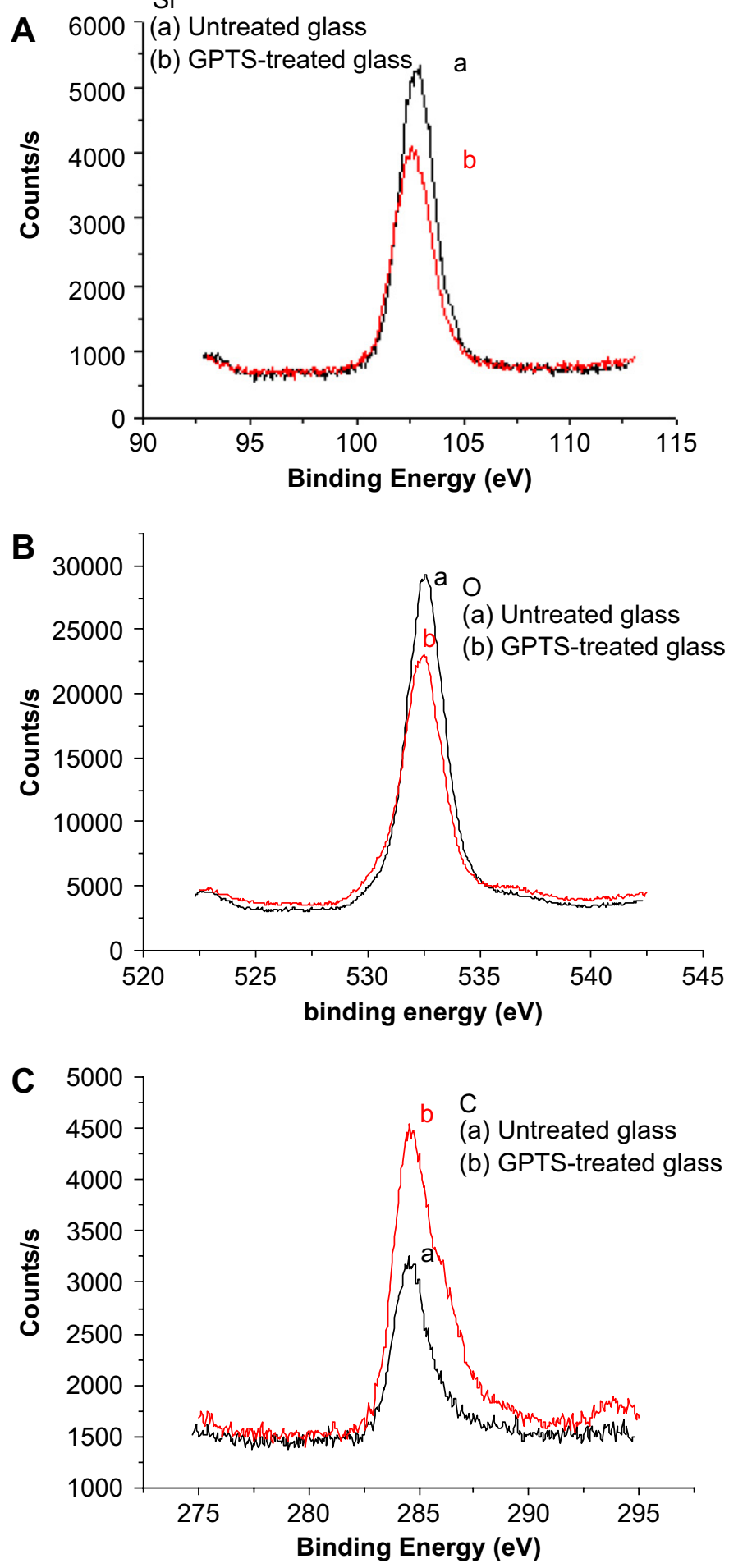

Fig. 4. The spectrum of X-ray photoelectron spectroscopy. X-ray photoelectron (A) $\mathrm{Si}_{2 p}$ spectra, (B) $\mathrm{O}_{1 \mathrm{~s}}$ spectra and (C) $\mathrm{C}_{1 \mathrm{~s}}$ spectra for untreated and GPTS-treated glass.

the modification process, proving that silane groups were indeed immobilized onto the glass substrate (Fig. 3E, F).

\section{XPS}

X-ray photoelectron spectroscopy (XPS) can analyze the chemical bonding and the substrate surface elemental compositions. By semi-quantification of the three elements $\mathrm{Si}, \mathrm{O}$, and $\mathrm{C}$, we can realize that the silanisation process was achieved by modification
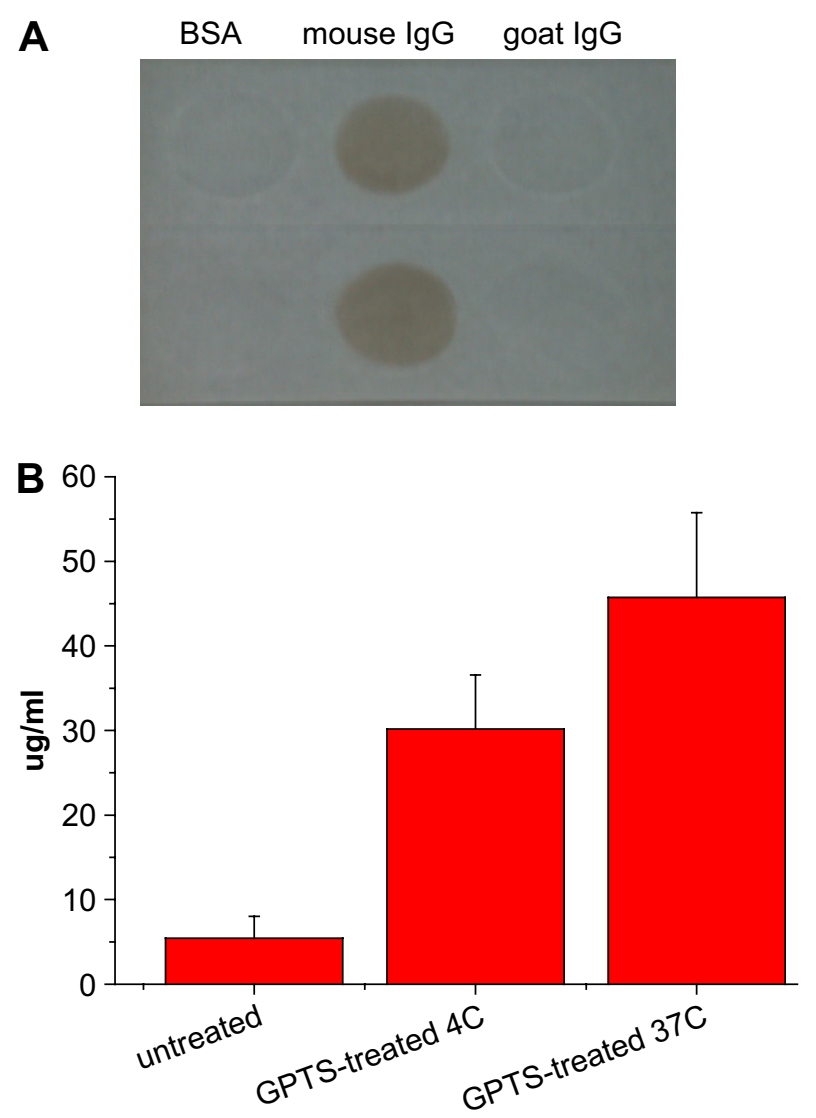

Fig. 5. (A) Direct enzyme-linked immunosorbent assay (ELISA) for specific antibody detection test. Different proteins including BSA, mouse $\operatorname{IgG}$ and goat $\operatorname{IgG}$, respectively, were immobilized onto the glass substrate and then detected by goat anti-mouse IgG secondary antibody. (B) The analysis of the immobilization degree at different conditions, $n=4$.

process. In Fig. 4, the results showed that GPTS-treated glass surface possessed higher amounts of C element (Fig. 4C), while the Si and O elements were decreased as compared to the untreated glass specimens (Fig. 4A, B). The result confirms that silane groups were successfully grafted onto the surface of glass substrate.

\subsection{Enzyme-linked immunosorbent assay (ELISA)}

Next, the enzyme-linked immunosorbent assay was used to investigate whether immuno proteins could be successfully immobilized onto silane-modified glass substrate, and whether the immobilized protein could actively react with the specific corresponding antibody. In Fig. 5A, the result shows that only mouse IgG protein was positively stained with goat anti-mouse IgG secondary antibody in HRP system, while BSA and goat IgG protein were all negatively present. This claims that after immobilization process, immuno protein could still maintain its function and exhibit no unspecific cross binding reactions. The degree of protein immobilization is also illustrated in Fig. 5B. The result shows that GPTStreated glass substrate was able to conjugate more amounts of proteins than untreated one. In addition, the effect of reaction temperature at $37^{\circ} \mathrm{C}$ was better than that at $4{ }^{\circ} \mathrm{C}$.

The detection of anti-EBNA1 IgA antibody protein in different serum specimens by enzyme-linked immunosorbent assay was illustrated in Fig. 6. The data demonstrates that there exists significant difference of EBNA1 IgA protein level between normal and NPC patient's serum using this detection system (Fig. 6A). We then serially diluted the concentration of biotinylated goat antihuman IgA secondary antibody and found that even at the 

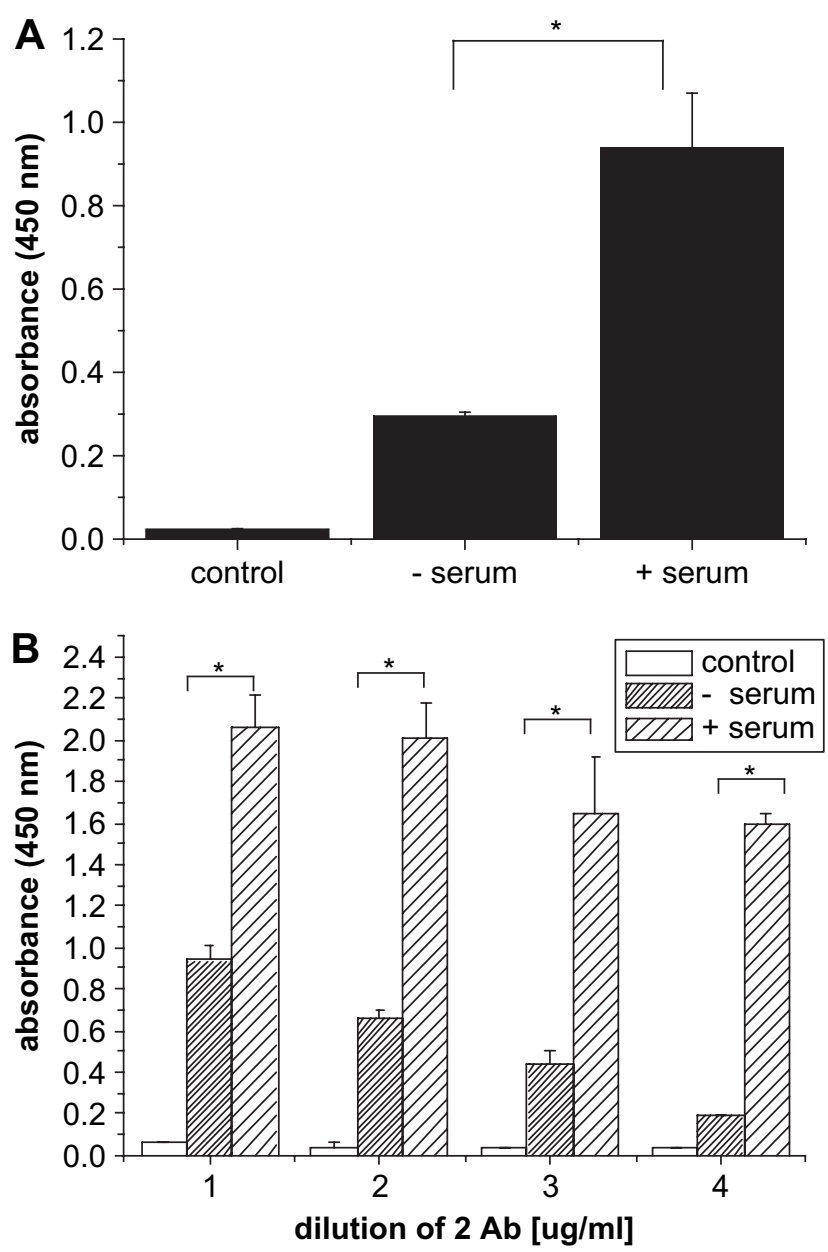

Fig. 6. (A) The OD value of the result of anti-EBNA1 IgA antibody level. (Control: without serum addition; -serum: normal people's serum; +serum: NPC patient's serum; $\left.n=4 ;{ }^{*} p<0.01\right)$. (B) Analysis of diluted concentration of biotinylated goat antihuman IgA secondary antibody $(1: 0.5 \mu \mathrm{g} / \mathrm{ml} ; 2: 0.25 \mu \mathrm{g} / \mathrm{ml} ; 3: 0.1 \mu \mathrm{g} / \mathrm{ml} ; 4: 0.075 \mu \mathrm{g} /$ $\left.\mathrm{ml} ; n=4 ;{ }^{*} p<0.01\right)$.

concentration of $0.075 \mu \mathrm{g} / \mathrm{ml}$, the system could still obviously detect and allow clear discrimination in the difference between normal and NPC patient's EBNA1 protein level in the serum (Fig. 6B). The commercialized ELISA kit was also used to compare with our developed system. In Fig. 7A, we can find that the result of our immunosorbent assay system was more precisely interpreted. Among the five NPC specimens, they were all positively detected in our system as compared with the normal specimens, while there were only three samples examined as positive in commercialized system. It proves that the sensitivity and affinity were very high and satisfactory in our established immunosorbent assay system. Continuously, the detection limitation of our system was performed by serial dilution of the sample serum. It was until 2000-fold dilution that it appears no significant difference between normal and NPC patient's serum (Fig. 7B). This would be explained as the limitation of our system.

\section{Immuno-PCR}

In Fig. 8, a specific 235-bp PCR product was observed in lanes, which indicates that the biotinylated target DNA was specifically attached to the antigen-monoclonal antibody complexes by the streptavidin-biotin chimera. However, when the concentration of biotinylated DNA was excess $1 \mathrm{ng} / \mathrm{ml}$, there would be unspecific binding resulting in false positive signal expression (Fig. 8A). In the following experiments, the concentration of biotinylated DNA was
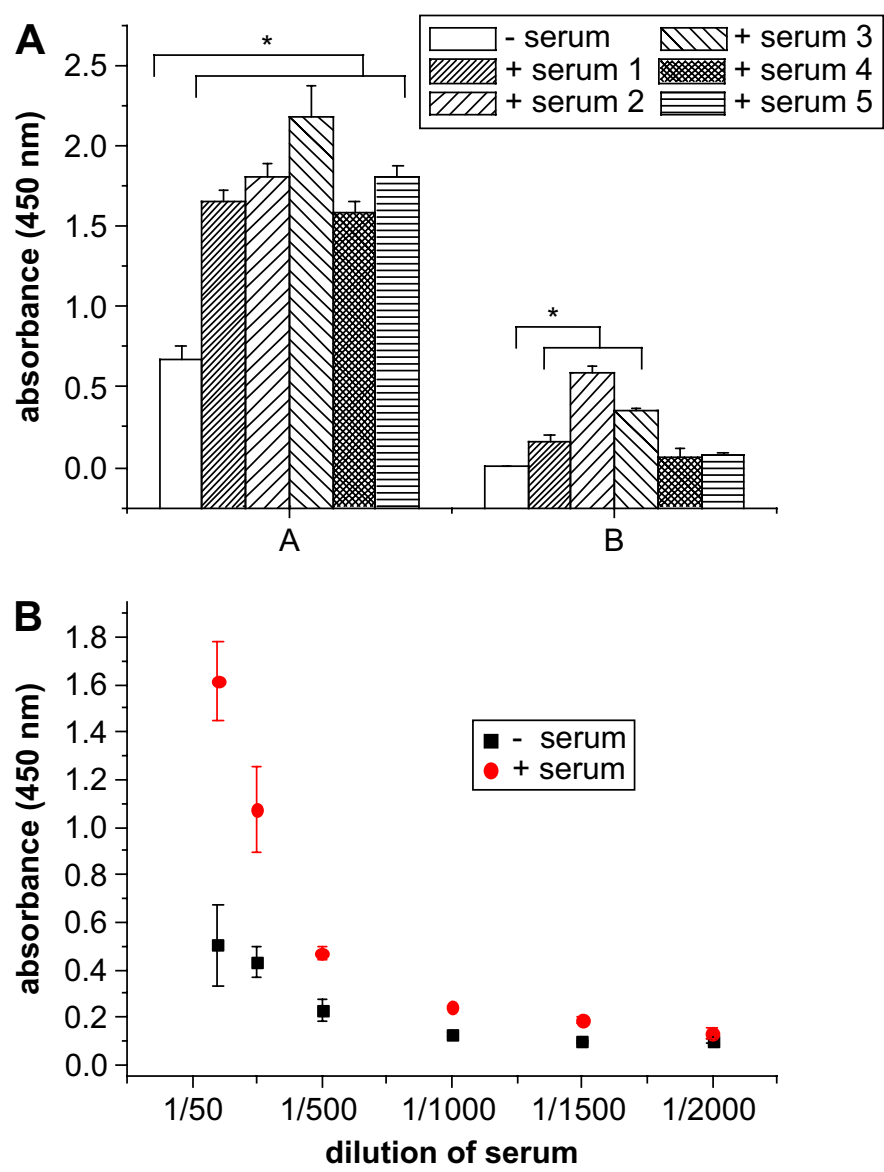

Fig. 7. (A) Comparison in the sensitivity and efficiency of commercialized ELISA kit with our developed immunosorbent assay system (A: our system; B: commercialized ELISA system; -serum: normal people's serum; +serum: NPC patient's serum; $\left.{ }^{*} p<0.01\right)$. (B) The concentration limitation test of our detection system. (1/50: dilution for 50 -fold, etc.; mean $\pm S D ; n=4$ ).

chosen at $1 \mathrm{ng} / \mathrm{ml}$ to avoid unspecific binding reaction. The optimal concentration of streptavidin was also evaluated in this study. In Fig. $8 \mathrm{~B}$, it demonstrates that the concentration of streptavidin should be controlled at the value of $100 \mathrm{ng} / \mathrm{ml}$. If the concentration continuously increased, there would be false positive signal expression in normal specimens; on the other hand, if the concentration decreased, there would be lost of signal expression in NPC patient's serum specimens. In the next step, the optimal concentration of biotinylated goat anti-human IgA secondary antibody was studied. The result shows that when the concentration was over $0.075 \mu \mathrm{g} / \mathrm{ml}$, false positive signal would appear in normal serum specimens (Fig. 8C). It suggests that we should not apply higher than this concentration. Finally, the sensitivity and limitation of our IPCR system were investigated by serial dilution of NPC patient's serum specimens (Fig. 9). Three specimens were examined in this study (Fig. 9A, B). After dilution for 15,000-fold, two of these samples were all with positive results suggesting that our IPCR system possesses sufficient sensitivity to make obvious discrimination of positive signals as compared with another one sample using conventional ELISA system, in which the signal was absent when diluted to 3000-fold (Fig. 9C). In the following studies, we will include more test subjects to survey the accuracy and build up the reliability for the database.

\section{Discussion}

In this study, we chose EBV nuclear antigen (EBNA1) IgA protein as Epstein-Barr virus (EBV) marker protein, because it is reported 


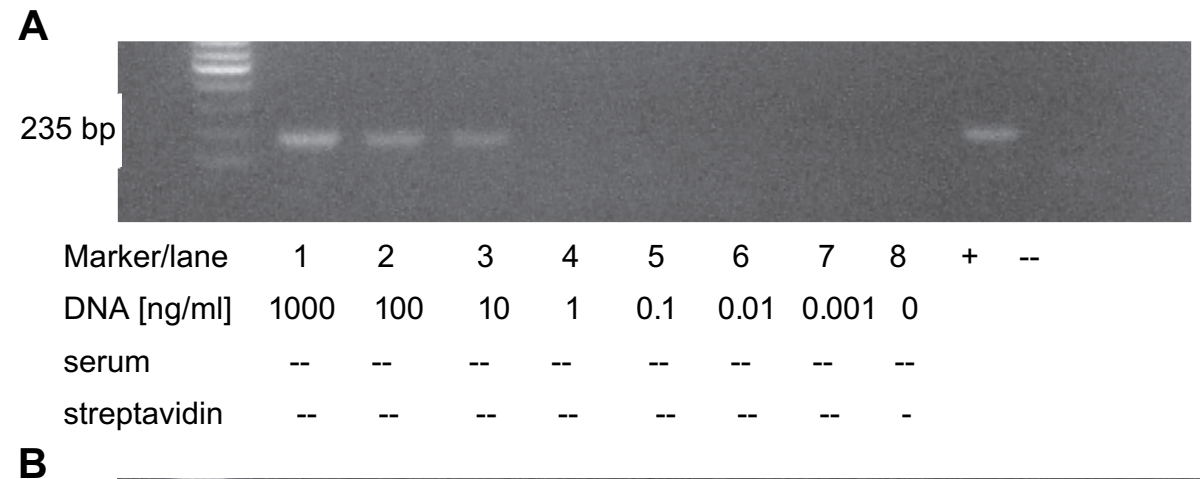

B

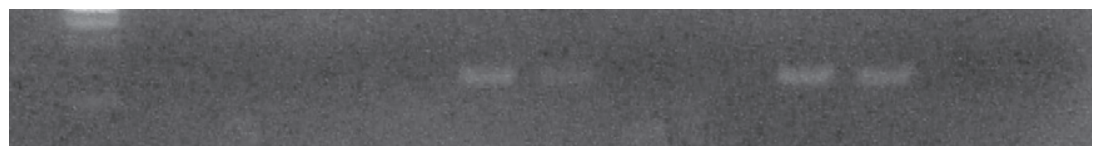

$\begin{array}{lcccccccccccc}\text { Marker/lane } & 1 & 2 & 3 & 4 & 5 & 6 & 7 & 8 & 9 & 10 & 11 & 12 \\ \text { Serum } & -- & -- & -- & -- & -- & -- & -- & -- & + & + & + & + \\ \text { STV [ng/ml] } & 1000 & 100 & 10 & 1 & 1000 & 100 & 10 & 1 & 1000 & 100 & 10 & 1\end{array}$

C

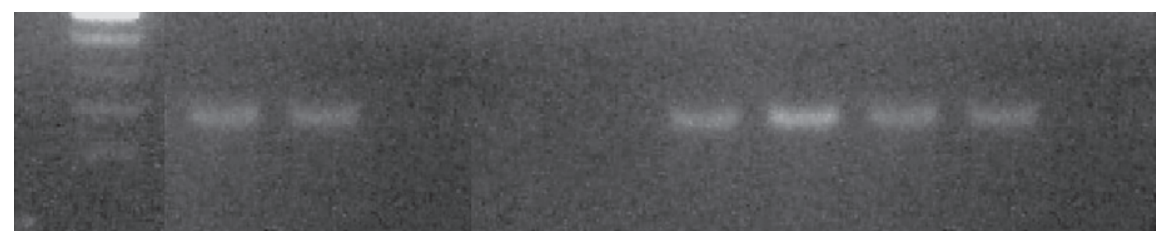

$\begin{array}{lcccccccccc}\text { Marker/lane } & 1 & 2 & 3 & 4 & 5 & 6 & 7 & 8 & 9 & 10 \\ \text { DNA [ng/ml] } & 1 & 1 & 1 & 1 & 1 & 1 & 1 & 1 & 1 & 1 \\ \text { Serum } & -- & -- & -- & -- & -- & + & + & + & + & + \\ \text { 2-Ab[ug/ml] } & 0.25 & 0.1 & 0.075 & 0.05 & 0 & 0.25 & 0.1 & 0.075 & 0.05 & 0\end{array}$

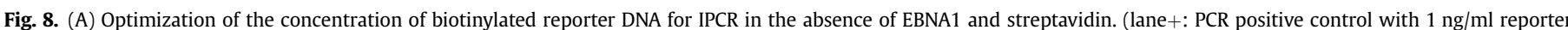

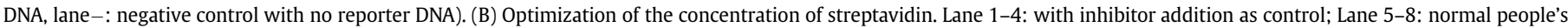

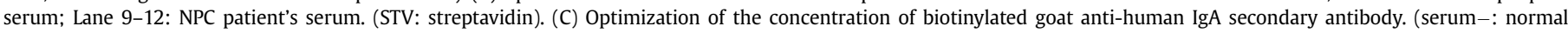
people's serum without EBNA1 protein; serum+: NPC patient's serum with EBNA1 protein; $n=4$ ).

A

$235 \mathrm{bp}$

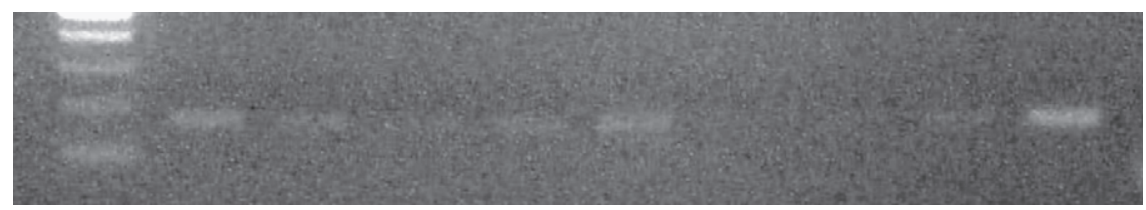

B

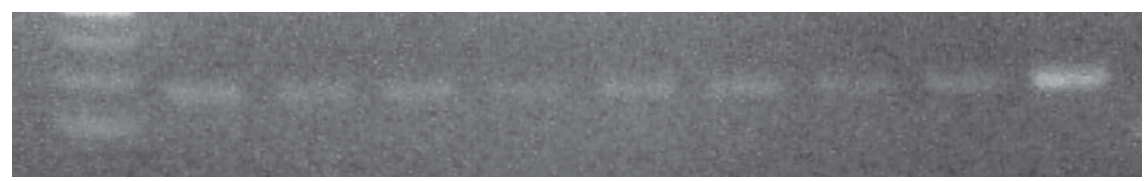

C

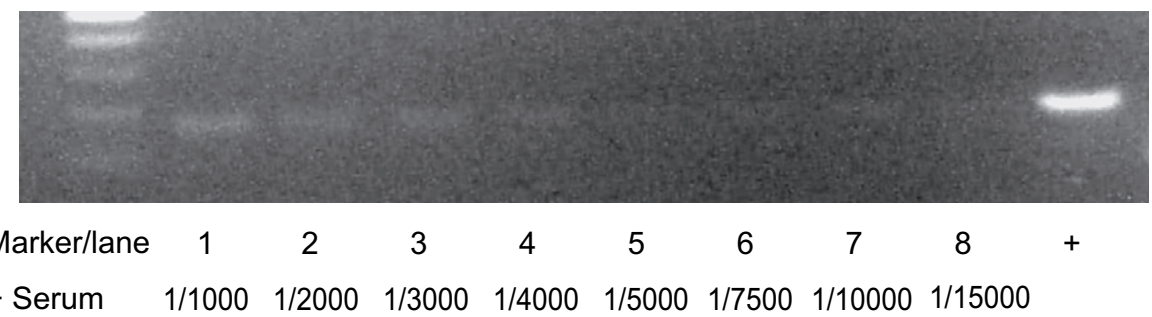

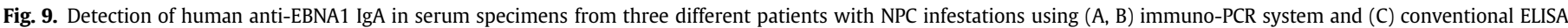
system. Serum was serially diluted from $1 \times 10^{-3}$ to $15 \times 10^{-3}$. Lane M: DNA molecular weight markers. Lane+: PCR positive control (10 ng/ml reporter DNA). 
that elevated titers of antibodies to the EBV, particularly the $\operatorname{IgA}$ subtypes, are found in patients with NPC. The EBNA1 protein binds to viral DNA and allows the EBV genome to be maintained in the $\mathrm{B}$ cell as a circular DNA episome [10]. IgA antibody titers to the EBV viral capsid antigen and to the EBV early antigen (EBV IgA-EA) are used for the serologic screening and diagnosis of NPC in many research studies $[11,12]$.

Silane coupling agents are commonly used to activate substrate surfaces for subsequent immobilization of biomolecules [13]. The tailed epoxide ring is reactive toward nucleophiles such as amines, thiols, alcohols and acids, and can be used for subsequent coupling to form functional linkages. Our procedure for functionalizing a typical silicon-based surface involves condensation of the methoxy groups in GPTS with surface silanol groups using a dry aromatic solvent, toluene, as the catalyst. In the presence of excess moisture, GPTS crosslinks and polymerizes. Methoxy groups attached to silicon are converted in the presence of water to form methanol and silanol. Silanols can condense easily with each other or with another methoxy group attached to another $\mathrm{Si}$ atom to form siloxane bonds [14]. It suggests that the homogeneity and surface morphology of silane films are important for controlling the structural order of immobilized single-stranded DNA probes $[15,16]$. In this study, the AFM was conducted to examine the roughness and morphology of the glass surface. After piranha solution treatment, the $3 \mathrm{D}$ image showed more homogeneous surface morphology without uneven sharp spikes (Fig. 3). The XPS study by analyzing the change in elemental composition of the modified glass substrate surface (Fig. 4) as well as water angle measurement by investigating the hydrophilic property on the surface (Fig. 2) was all in agreement with and supportive of the previous AFM results.

Immuno-PCR (IPCR) combines the standard ELISA technology with the signal amplification power and fast read-out of the realtime PCR [17]. Advantages of IPCR include minimized sample volume requirements, high tolerances against drug and matrix effects and its adaptability for the detection of basically any antigen [18]. The basic principle relies upon detection of antigen-bound antibody by the sequential use of (i) a second antibody-streptavidin conjugate directed against the primary antibody, (ii) a biotinylated target DNA which binds streptavidin with high affinity, and (iii) PCR for the detection of the immobilized target DNA. We here reported on the development of an IPCR system, which is based on the chemically modified glass substrates. To elucidate the performance of IPCR, we chose the detection of EBNA1 in human serum as a model system. We first conjugate EBNA1 antigens on the glass substrate surface enabling reaction with EBNA1 antibodies in NPC patient's serum, then binding to the biotinylated secondary antibody followed by complexing with streptavidin molecules, and finally tailed with a biotinylated DNA fragment for the purpose of PCR amplification. The general scheme of this assay is based on a two-sided sandwich immunoassay and demonstrates in Fig. 1. In this study, a streptavidin (STV) protein, comprising four binding sites to conjugate biotinylated secondary anti-human IgA antibody with biotinylated target DNA, was used as a linker unit. The protein EBNA1-STV chimera can be used to link the secondary antibody with biotinylated double-stranded DNA by simply mixing a stoichiometric ratio of the three components. This approach increases both the sensitivity and precision of IPCR detection (Fig. 6)

The performance of IPCR assays could be significantly enhanced by the use of pre-synthesized protein-DNA conjugates, connected by either supramolecular mechanisms or by covalent coupling chemistry. However, the production of the latter is cumbersome because many antibodies are too unstable to withstand the harsh conditions of the chemical coupling and, in particular, chromatographic purification steps [19]. The assembly of signal-generating complexes in situ by successive incubation steps opened up a practicable route to establish IPCR assays without the necessity of cumbersome synthesis and purification of antibody-DNA conjugates.

The efficacy of PCR is based on its ability to amplify a specific DNA segment flanked by a set of primers. The extremely high specificity of PCR for a target sequence defined by a set of primers should avoid the generation of false signals from other nucleic acid molecules present in samples. Because the sequences of a marker DNA and its amplified segment are purely arbitrary, they can be changed frequently, if needed, to prevent deterioration of signalto-noise ratios caused by contamination. Thus, one can control the sensitivity of the system by varying the concentration of the conjugate. Other key factors, such as the concentration of antibody, the number of PCR amplification cycles, and the detection method for PCR products, can also be used to control the overall sensitivity of the system. In this study, we have minimized this phenomenon by the investigation of the optimal concentration of biotinylated reporter DNA, streptavidin, and biotinylated goat anti-human IgA secondary antibody in our IPCR system (Fig. 8).

The capability of antigen detection systems could be considerably enhanced and potentially broadened by coupling to PCR detectable antigens [20]. In our IPCR system, a linker streptavidin molecule with bi-specific binding affinity for DNA and antibodies is used to attach a DNA marker molecule specifically to an antibodyantigen complex, resulting in the formation of a specific antigenantibody-DNA conjugate. The attached marker DNA can then be amplified by PCR with the appropriate primers. The presence of specific PCR products demonstrates that marker DNA molecules are attached specifically to antigen-antibody complexes, which indicates the presence of antibody in the human plasma (Fig. 9). The commercialized ELISA system was also included for comparison in this study. Our works have increased the sensitivity for the IPCR system, as compared with the analogous commercialized ELISA kit (Fig. 7A). As established by numerous examples, a 100-1000-fold improvement in common ELISA sensitivity is generally accessible when a given ELISA is adapted to an IPCR assay [21,22]. In our results, after dilution with 1500 -fold of NPC patient's serum specimen, IPCR system could still detect the difference between normal and patient's EBNA1 IgA in serum level. The limitation was obtained when the specimens were diluted to 2000-fold (Fig. 7B).

Although the detection on anti-EBNA1 for NPC is very specific and highly sensitive, when a patient is treated by radiotherapy or chemotherapy, the concentration of EBNA1 in serum could temporary lower down to the level comparable to normal subjects. This would make it difficult to be distinguished by the system. Thus, IPCR system is useful for early NPC disease diagnosis and may have its limitations on the later detection stage. So, the interpretation of the reading result once medical intervention has been given must be very careful.

\section{Conclusion}

Immuno-PCR is a novel technology for antigen detection, combining the versatility of established ELISA techniques with the sensitivity of nucleic acid analyses. In this study, the bifunctional streptavidin specificity both for biotin and antibody allows the specific conjugation of any biotinylated DNA molecule to antigenantibody complexes. This result demonstrates the specific detection of immobilized antigen by IPCR. The 235-bp reporter DNA fragment was clearly observed even with only small amount of antibody titers. Direct comparison with commercialized ELISA kit shows that enhancement approximately two order magnitude in detection sensitivity was obtained with the use of IPCR instead of ELISA. In principle, the extremely high sensitivity of IPCR should enable this technology to be applied to the early detection of nasopharyngeal carcinoma. The controllable sensitivity and the 
simple procedure of IPCR should allow the development of fully automated assay systems without loss in sensitivity, with a great potential promise for applications in NPC early diagnostics.

\section{References}

[1] Wilson JB, Bell JL, Levine AJ. Expression of Epstein-Barr virus nuclear antigen1 induces B cell neoplasia in transgenic mice. EMBO J 1996;15(12):3117-26.

[2] Wei WI, Sham JS. Nasopharyngeal carcinoma. Lancet 2005;365(9476):204154.

[3] Sano T, Smith CL, Cantor CR. Immuno-PCR: very sensitive antigen detection by means of specific antibody-DNA conjugates. Science 1992;258(5079):120-2.

[4] Niemeyer CM, Adler M, Wacker R. Immuno-PCR: high sensitivity detection of proteins by nucleic acid amplification. Trends Biotechnol 2005;23(4):208-16.

[5] Adler M, Langer M, Witthohn K, Eck J, Blohm D, Niemeyer CM. Detection of rViscumin in plasma samples by immuno-PCR. Biochem Biophys Res Commun 2003;300(3):757-63.

[6] Joerger RD, Truby TM, Hendrickson ER, Young RM, Ebersole RC. Analyte detection with DNA-labeled antibodies and polymerase chain reaction. Clin Chem 1995;41(9):1371-7.

[7] Saito K, Kobayashi D, Sasaki M, Araake H, Kida T, Yagihashi A, et al. Detection of human serum tumor necrosis factor-alpha in healthy donors, using a highly sensitive immuno-PCR assay. Clin Chem 1999;45(5):665-9.

[8] Wong AK, Krull UJ. Surface characterization of 3-glycidoxypropyltrimethoxysilane films on silicon-based substrates. Anal Bioanal Chem 2005;383(2): 187-200.

[9] Mweene AS, Ito T, Okazaki K, Ono E, Shimizu Y, Kida H. Development of immuno-PCR for diagnosis of bovine herpesvirus 1 infection. J Clin Microbiol 1996;34(3):748-50.

[10] Cohen JI. Epstein-Barr virus infection. N Engl J Med 2000;343(7):481-92.

[11] Tsang RK, Vlantis AC, Ho RW, Tam JS, To KF, van Hasselt CA. Sensitivity and specificity of Epstein-Barr virus IGA titer in the diagnosis of nasopharyngeal carcinoma: a three-year institutional review. Head Neck 2004;26(7):598602.

[12] Chien YC, Chen JY, Liu MY, Yang HI, Hsu MM, Chen CJ, et al. Serologic markers of Epstein-Barr virus infection and nasopharyngeal carcinoma in Taiwanese men. N Engl J Med 2001;345(26):1877-82.

[13] Piehler J, Brecht A, Valiokas R, Liedberg B, Gauglitz G. A high-density poly(ethylene glycol) polymer brush for immobilization on glass-type surfaces. Biosens Bioelectron 2000;15(9-10):473-81.

[14] Maskos U, Southern EM. Oligonucleotide hybridizations on glass supports: a novel linker for oligonucleotide synthesis and hybridization properties of oligonucleotides synthesised in situ. Nucleic Acids Res 1992;20(7): 1679-84.

[15] Ulman A. Formation and structure of self-assembled monolayers. Chem Rev 1996;96:1533-54.

[16] Plueddemann EP. Silane coupling agents. New York: Plenum Press; 1982

[17] Lind K, Kubista M. Development and evaluation of three real-time immunoPCR assemblages for quantification of PSA. J Immunol Methods 2005;304(12):107-16.

[18] Adler M, Wacker R, Niemeyer CM. A real-time immuno-PCR assay for routine ultrasensitive quantification of proteins. Biochem Biophys Res Commun 2003;308(2):240-50.

[19] Hendrickson ER, Truby TM, Joerger RD, Majarian WR, Ebersole RC. High sensitivity multianalyte immunoassay using covalent DNA-labeled antibodies and polymerase chain reaction. Nucleic Acids Res 1995;23(3):522-9.

[20] McKie A, Samuel D, Cohen B, Saunders NA. A quantitative immuno-PCR assay for the detection of mumps-specific IgG. J Immunol Methods 2002;270(1): $135-41$.

[21] Niemeyer CM, Adler M, Blohm D. Fluorometric polymerase chain reaction (PCR) enzyme-linked immunosorbent assay for quantification of immuno-PCR products in microplates. Anal Biochem 1997;246(1):140-5.

[22] Adler M, Wacker R, Booltink E, Manz B, Niemeyer CM. Detection of femtogram amounts of biogenic amines using self-assembled DNA-protein nanostructures. Nat Methods 2005;2:147-9. 